\title{
Association between ultrasound findings, tumor type, grade, and biological markers in patients with breast cancer
}

\author{
Yasmine Mohamed Elsaeid ${ }^{1}$, Dina Elmetwally ${ }^{2^{*}}$ and Salwa Mohamed Eteba ${ }^{2}$
}

\begin{abstract}
Background: This prospective study included 65 female patients with primary breast cancer. Ultrasound was performed for all patients. Ultrasound findings were analyzed according to the ACR BI-RADS lexicon 5th edition and correlated with tumor type, grade, and biological markers (ER, PR, HER-2/neu, and Ki67). The purpose of this study is to assess the association between ultrasound findings, tumor type, grade, and the state of biological markers in patients with breast cancer.

Results: Irregular shape and speculated margins are more frequently associated with invasive duct carcinoma than DCIS ( $p$ value $<0.001$ ). There were no association between the ultrasound findings (shape, margin, orientation, echopattern, and posterior features) and the tumor grade ( $p$ value 1.0, 0, 0.544, 1.0, and 1.0), respectively. Irregular shape is more frequently seen in ER and PR positive breast cancers ( $p$ value $=0.036$ and 0.026 , respectively). Noncircumscribed margins were frequently seen in PR positive breast cancers ( $p$ value $=0.068$ ). No statistically significant difference between US descriptors and HER-2/neu-positive cases.
\end{abstract}

Conclusion: Irregularly shaped tumors with speculated margins are frequently seen in invasive duct carcinoma and also more frequently seen in ER-, PR-, and Ki67-positive cases. No relation between ultrasound descriptors and the tumor grade of invasive duct carcinoma. Also, there were no relation between ultrasound descriptors and the state of HER-2/neu.

Keywords: Ultrasound, Breast cancer, Tumor type, Tumor grade, Biological markers

\section{Background}

Breast ultrasound (US) is widely used as a diagnostic modality for evaluating suspected breast abnormalities. Also, it is considered as an effective imaging modality for detecting occult carcinomas in patients with dense breasts $[1,2]$.

In general, the imaging criteria (tumor shape, margin, and density by mammography, tumor shape, margin, orientation, echo pattern, and posterior features by ultrasound) for diagnosis of breast cancer by various imaging modalities as mammogram, ultrasound, and MRI have been studied for a long time, and this allowed differentiation between benign and malignant breast tumors with some certainty, as outlined in the current imaging

\footnotetext{
* Correspondence: elmetwallydina@gmail.com

${ }^{2}$ Diagnostic Radiology and Medical Imaging, Faculty of Medicine, Mansoura

University, Mansoura, Egypt

Full list of author information is available at the end of the article
}

criteria used in the BI-RADS (breast-imaging reporting and data system) [3].

The standard prognostic indicators in patients with breast cancer are histological tumor type, tumor grade, and tumor staging [4]. Other prognostic indicators are the biological markers [5]. Common biological markers include estrogen receptor (ER), progesterone receptor (PR), and human epithelial growth factor receptor (HER). ER and PR are present in the nuclei of epithelial cells, and their existence predicts tumor response to hormonal therapy [6]. The HER-2/neu gene is a member in the HER family. It is responsible for organization of normal development of the cell. Trastuzumab usually targets the cells that show HER-2/neu overexpression [7].

Some studies focused on the role of ultrasound to predict tumor type and tumor grade [8-15], also some studies have focused on correlation between US findings and the presence of biological markers $[9,10,15,16]$. 
So, the purpose of this study was to assess if there is an association between ultrasound findings, tumor type, tumor grade, and the state of biological markers in patients with breast cancer.

\section{Methods}

\section{Patient's demographic data}

This prospective study was performed on 65 female patients with primary breast cancer. Their age ranged from 36 to 85 years with a mean age of 54.95 . It was performed during the period from January 2018 till January 2019 and was approved by our institution's ethics committee. All patients gave their informed consent before inclusion in the study.

Inclusion criteria included female patients with primary breast cancer. Exclusion criteria included patients who received neoadjuvant chemotherapy, patients who underwent prior surgery for breast cancer, and patients who refused to participate in the study.

\section{Ultrasound technique}

The ultrasound examination was performed using Toshiba Aplio 500. Radial and antiradial scanning of the entire breast and axillary tail of both sides were obtained with image overlap using high-frequency 8$14 \mathrm{MHz}$ linear transducer with $\mathrm{B}$. mode US real-time imaging and Doppler flow mapping. Image depth adjusted on the machine to visualize pectoralis major muscle (at least $4 \mathrm{~cm}$ ).

\section{Image interpretation}

Images were interpreted by an expert radiologist (10 years' experience in breast imaging). Tumor criteria were evaluated according to the ACR BI-RADS atlas 5th edition [3]. The assessed criteria were tumor shape (round or oval versus irregular), margin (circumscribed versus not circumscribed), and "not circumscribed" margins which include indistinct, spiculated, angular or microlobulated margins, orientation (parallel versus non-parallel), echo pattern (hypoechoic or complex versus isoechoic or hyperechoic), and posterior acoustic feature (shadowing or combined posterior acoustic feature versus no posterior acoustic feature or enhancement).

\section{Ultrasound-guided core}

Biopsies of the breast were performed for all cases using 14-gauge needle. Multiple core biopsies were taken from different part of lesions to analyze tumor type, grade, and hormonal receptors.

\section{Pathological and immunohistochemical analysis}

Histological tumor types of our study were divided into invasive ductal cancers and ductal carcinoma in situ (DCIS). Invasive cancer was graded as grade 1 (well differentiated), grade 2 (moderately differentiated), or grade 3 (poorly differentiated). DCIS cases were classified as group 1 (non-high grade DCIS without comedotype necrosis), group 2 (non-high grade DCIS with comedo-type necrosis), or group 3 (high-grade DCIS with or without comedo-type necrosis).

Staining was performed for ER, PR, HER/neu-2, and Ki67. ER and PR positivity was defined as the presence of at least $1 \%$ positive tumor nucleus in the sample. HER/neu-2 expression was scored as $(1+, 2+$, or $3+)$. Tumors with a score of $3+$ were classified as HER/neu-2 positive and tumors with scores of 0 or $1+$ were classified as HER/neu-2 negative. Ki 67 was reported as the percentage of total number of tumor cells with nuclear staining. A percentage of more than or equal $14 \%$ defined positive ki67 status.

\section{Statistical analysis}

SPSS (Statistical Package for Social Sciences) version 23.0 was used for data management and data analysis. Qualitative data were expressed as count and percent. Quantitative data were expressed as mean \pm standard deviation (SD) if normally distributed or median and interquartile range (IQR) if not. For data comparison, onesample chi-square test was used for qualitative data for one group. Chi-square test (or Fisher's exact test) was used for qualitative data for two groups $(2 \times 2$ table) . Chi-square test (with Bonferroni method to adjust $p$ values when comparing column proportions) was used for qualitative data for more than two groups (e.g., $2 \times 3$ table). For comparing quantitative data between two groups, independent sample $t$ test was used if data were normally distributed in both groups. The nonparametric alternative Mann-Whitney $U$ test was used if not. For any of the used tests, results were considered as statistically significant if $p$ value $\leq 0.050$.

\section{Results}

This prospective study included 65 female patients with age ranged between 36 and 85 years with a mean age 54.95 .

Out of the 65 patients included in this study, there were 52 patients $(80.0 \%)$ with invasive duct carcinoma and 13 patients $(20.0 \%)$ with DCIS. The most frequent tumor grade was grade II invasive cancer detected in 30 patients $(57,7 \%)$. The most frequent grade of DCIS was grade II detected in 7 patients (53.8\%). Fifty-six patients $(86.2 \%)$ were estrogen receptor positive cases. Fortyseven patients $(72.3 \%)$ were progesterone receptorpositive cases. Thirty-seven patients $(56.9 \%)$ were HER2neu enriched and 48 patients $(73.8 \%)$ were ki67 index (Table 1).

When correlating the ultrasound findings with tumor type, we found that tumor shape and margins were the 
Table 1 Characteristics of 65 patients with malignant breast lesion

\begin{tabular}{|c|c|c|c|}
\hline & & Count & Percent \\
\hline \multirow[t]{3}{*}{ Tumor type } & Invasive cancer & 52 & 80.0 \\
\hline & DCIS & 13 & 20.0 \\
\hline & Total & 65 & 100.0 \\
\hline \multirow[t]{4}{*}{ Tumor grade of invasive cancer } & Grade I & 18 & 34.6 \\
\hline & Grade II & 30 & 57.7 \\
\hline & Grade III & 4 & 7.6 \\
\hline & Total & 52 & 100.0 \\
\hline \multirow[t]{4}{*}{ Tumor classification of DCIS } & Grade I & 3 & 23.1 \\
\hline & Grade II & 7 & 53.8 \\
\hline & Grade III & 3 & 23.1 \\
\hline & Total & 13 & 100.0 \\
\hline \multirow[t]{3}{*}{ Estrogen receptor } & Positive & 56 & 86.2 \\
\hline & Negative & 9 & 13.8 \\
\hline & Total & 65 & 100.0 \\
\hline \multirow[t]{3}{*}{ Progesterone receptor } & Positive & 47 & 72.3 \\
\hline & Negative & 18 & 27.7 \\
\hline & Total & 65 & 100.0 \\
\hline \multirow[t]{3}{*}{ HER-2/neu } & Positive & 37 & 56.9 \\
\hline & Negative & 28 & 43.1 \\
\hline & Total & 65 & 100.0 \\
\hline \multirow[t]{3}{*}{ KI67 } & Positive & 48 & 73.8 \\
\hline & Negative & 17 & 26.2 \\
\hline & Total & 65 & 100.0 \\
\hline
\end{tabular}

most important descriptors that can differentiate between invasive carcinoma and DCIS with irregular shape, and non-circumscribed margin were frequently seen in invasive cancer $p$ value $(<0.001)$ (Table 2$)$ (Figs. 1, 2, and 4). We also found that DCIS usually appeared as a non-mass lesion (area of parenchymal distortion), and this is observed in $46.2 \%$ of cases of DCIS included in the study (Table 2) (Fig. 3).

When correlating the ultrasound findings with the tumor grade, we found that ultrasound cannot differentiate between tumor grades of invasive duct carcinoma (Table 3).

When correlating the US findings with biological markers of breast cancer, we reported that irregular shape was more frequent in estrogen- and progesteronepositive cases with significant $p$ value $(0.036$ and 0.026 , respectively) (Tables 4 and 5) (Figs. 1, 2, and 4). Also, we reported that non-circumscribed margins were more frequent in progesterone-positive cases $(p$ value $=0.068)$ (Table 5) (Figs. 1, 2, and 4). We found that there were no statistically significant difference between US descriptors and HER-2/neu-positive cases (Table 6). Also, we reported that irregular shape and non-circumscribed margin had statistically significant difference in KI67positive cases ( $p$ values 0.050 and 0.047 , respectively) (Table 7) (Figs. 1 and 2).

\section{Discussion}

Breast cancer is the most frequently diagnosed cancer and the leading cause of cancer death among females worldwide [17]. The incidence of breast cancer in Egypt is $32.04 \%$ [18]. According to the WHO (World Health Organization), the incidence is $30 \%$ and mortality from breast cancer had increased recently in the younger women, so the main issue lies in the screening and early tumor detection to ensure an effective management and better prognosis [19].

Early detection of breast cancer and accurate assessment of lesions are the goals of various imaging modalities to ensure an effective management and better prognosis [20].

The response of breast cancer to therapy is influenced by many factors as tumor type, tumor grade, and the state of biological markers [10], so the aim of this study was to find association between ultrasound findings and tumor type, grade, and the state of biological markers.

In this study, when correlating the US descriptors with the tumor type, we found that the shape and the margin of the mass were the most important US descriptors to differentiate between invasive breast cancer and DCIS ( $p$ value $<0.001)$ with irregular shape, and speculated margin was more frequently seen in invasive cancer $(90.4 \%$ and $100 \%$, respectively), while most cases of DCIS were characterized by oval/rounded shape and smooth margins $(71.4 \%$ and $57.1 \%$, respectively) (Fig. 5). This is in agreement with the study done by Marino et al. [8], and they performed a study on 49 breast cancer patients and reported that irregular shape (78.6\%) and noncircumscribed margins (100\%) were more frequent in invasive cancer than DCIS ( $p$ value $<0.005$ ). Our results are also comparable with the study done by An et al. [9]. They performed a study on 52 breast cancer patients and concluded that irregular shape $(75.3 \%)$ and noncircumscribed margins (61.8\%) were more frequent in invasive cancer than DCIS ( $p$ value $=0.001$ ).

Our results reported that there was no statistically significant difference in posterior feature descriptor in differentiating between invasive cancers and DCIS ( $p$ value $=0.427$ ), and these results are concordant with the study done by Kim et al. [10], who stated that there was no statistical significant difference in posterior features between invasive cancers and DCIS ( $p$ value $=0.4552$ ).

We concluded that the other US descriptors (orientation and echopattern) cannot differentiate between invasive cancers and DCIS ( $p$ value $=0.604$ and 1.000, respectively). This is in agreement with the study done by Scoggins et al. [11], who reported that there was no 
Table 2 Association between tumor type and ultrasound findings of the breast cancers

\begin{tabular}{|c|c|c|c|c|c|c|}
\hline & & \multicolumn{4}{|c|}{ Tumor type } & \multirow{3}{*}{$p$ value } \\
\hline & & \multicolumn{2}{|c|}{ Invasive cancer } & \multicolumn{2}{|l|}{ DCIS } & \\
\hline & & Count & $\%$ & Count & $\%$ & \\
\hline \multicolumn{7}{|c|}{ Mass features } \\
\hline \multirow[t]{3}{*}{ Mass shape } & Oval/round & 5 & 9.6 & 5 & 71.4 & $<0.001$ \\
\hline & Irregular & 47 & 90.4 & 2 & 28.6 & \\
\hline & Total & 52 & 100.0 & 7 & 100.0 & \\
\hline \multirow[t]{3}{*}{ Mass margin } & Circumscribed & 0 & 0 & 4 & 57.1 & $<0.001$ \\
\hline & Non-circumscribed & 52 & 100 & 3 & 42.9 & \\
\hline & Total & 52 & 100.0 & 7 & 100 & \\
\hline \multirow[t]{3}{*}{ Mass orientation } & Parallel & 9 & 17.3 & 2 & 18.6 & 0.604 \\
\hline & Not parallel & 43 & 82.7 & 5 & 81.4 & \\
\hline & Total & 52 & 100.0 & 7 & 100.0 & \\
\hline \multirow[t]{3}{*}{ Mass posterior features } & No/enhancement & 20 & 38.5 & 4 & 57.1 & 0.427 \\
\hline & Shadowing/ combined & 32 & 61.5 & 3 & 42.9 & \\
\hline & Total & 52 & 100.0 & 7 & 100.0 & \\
\hline \multirow[t]{3}{*}{ Mass echopattern } & Hypoechoic & 46 & 88.5 & 7 & 100 & 1.000 \\
\hline & Heterogeneous & 6 & 11.5 & 0 & 0.0 & \\
\hline & Total & 52 & 100.0 & 7 & 100.0 & \\
\hline \multicolumn{2}{|c|}{ Non-mass features (architectural distortion) } & 0 & 0.0 & 6 & 100 & 0.004 \\
\hline
\end{tabular}

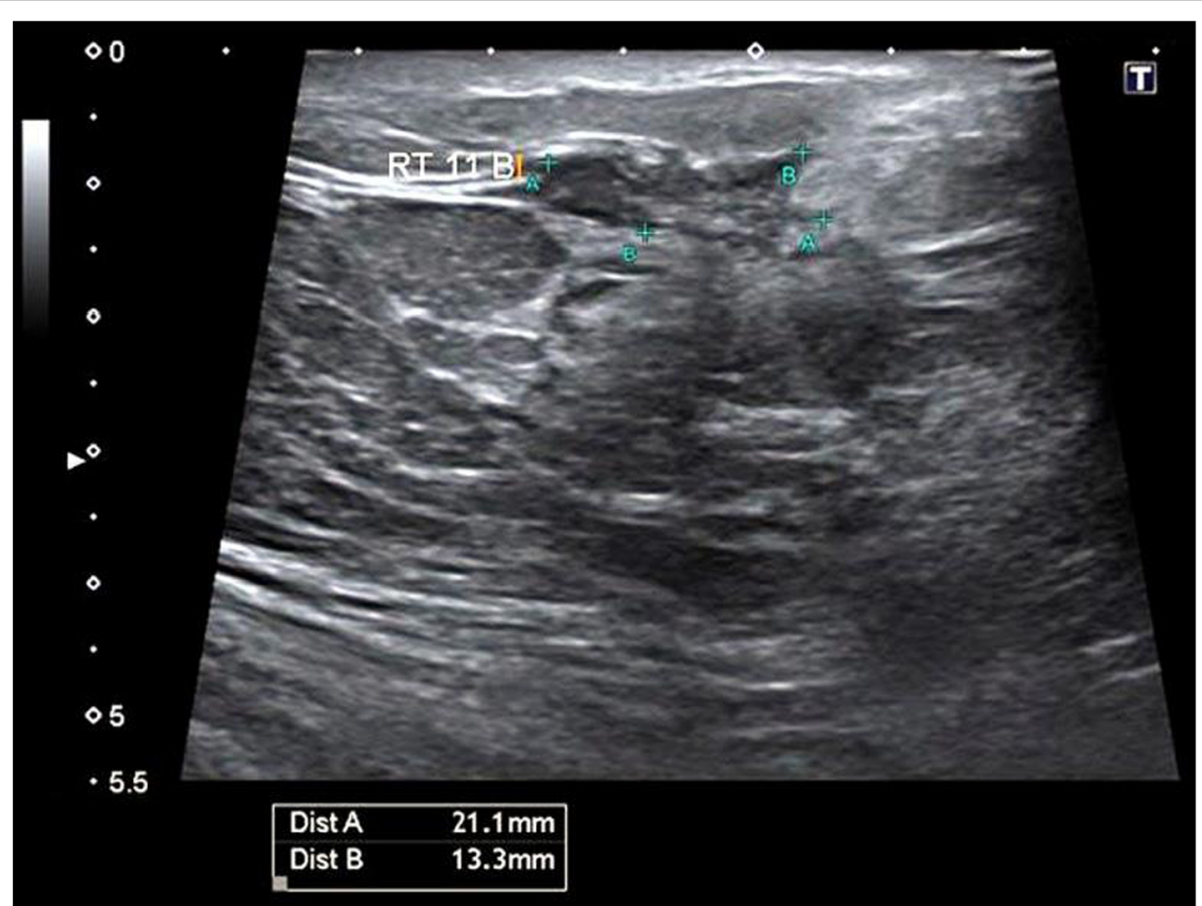

Fig. 1 B-mode US showed an irregular hypoechoic speculated solid mass with posterior shadowing measuring about $27 \times 18 \mathrm{~mm}$, assessed as BIRADS 5. Pathology: true cut biopsy revealed invasive ductal carcinoma grade II. Biological markers: ER positive, PR positive, HER/neu-2 negative, and Ki67 positive 


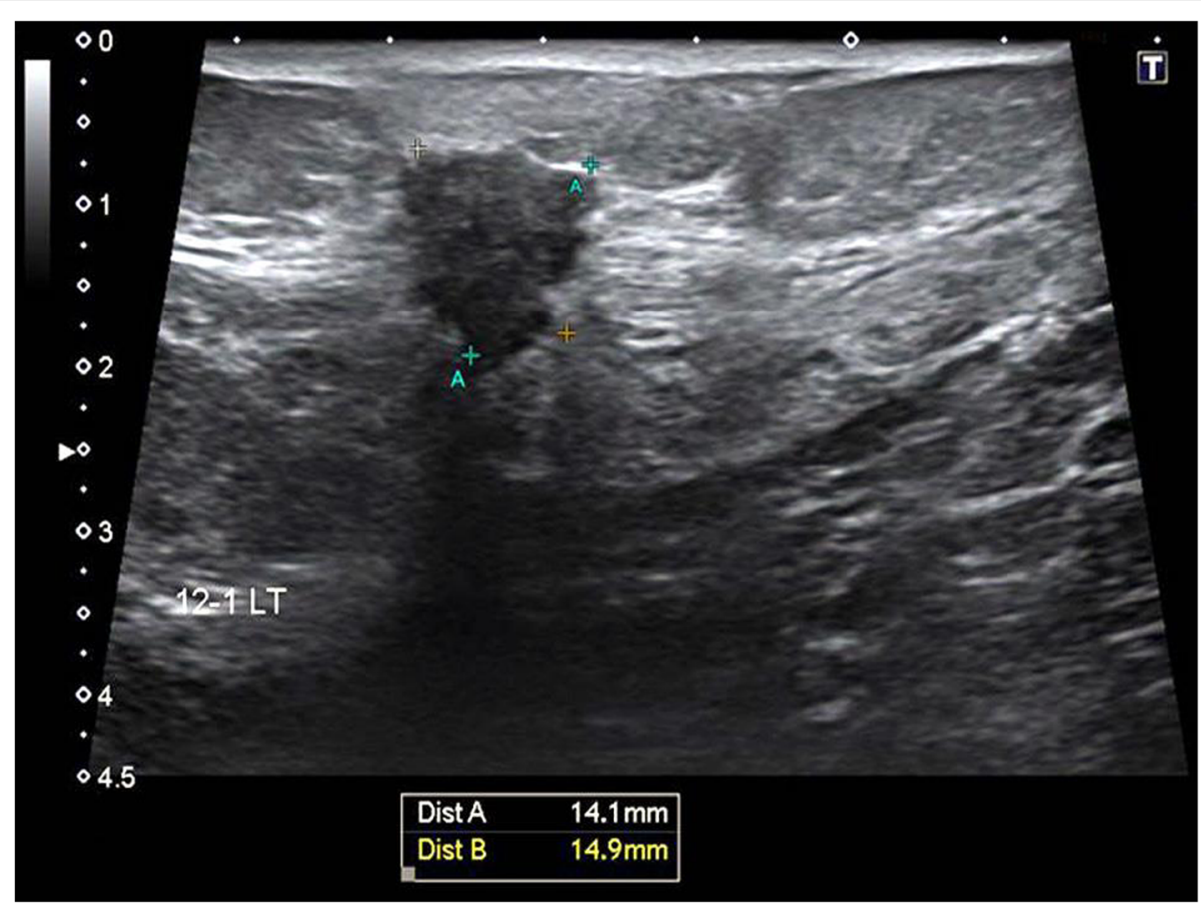

Fig. 2 B-mode ultrasound showed irregular hypoechoic speculated mass with antiparallel orientation and posterior shadowing measuring about $(14.1 \times 14.9 \mathrm{~mm})$, assessed as BIRADS 5. Pathology: true cut biopsy revealed infiltrating duct carcinoma grade III. Biological markers: ER positive, PR positive, HER/neu-2 negative, and Ki67 positive

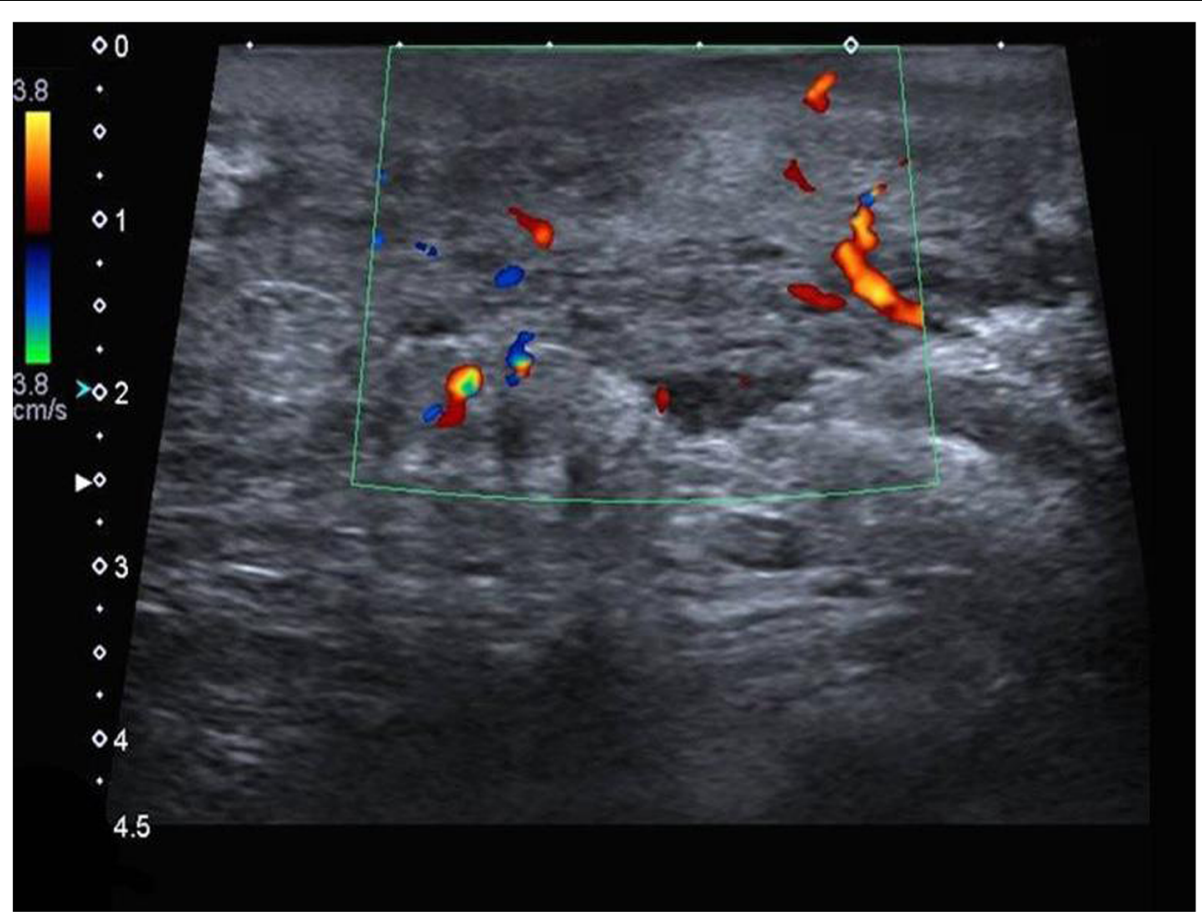

Fig. 3 B-mode ultrasound showed an ill-defined area of parenchymal distortion with marked internal vascularity, no definite masses, assessed as BIRADS 4C. Pathology: DCIS (grade II). Biological markers: ER positive, PR negative, HER/neu-2 positive, and Ki67 positive 
Table 3 Association between tumor grade and ultrasound findings of invasive breast cancers

\begin{tabular}{|c|c|c|c|c|c|c|}
\hline \multirow[t]{3}{*}{ Mass features } & & \multicolumn{4}{|c|}{ Tumor grade } & \multirow{3}{*}{$p$ value } \\
\hline & & \multicolumn{2}{|c|}{ Grade I + grade II } & \multicolumn{2}{|c|}{ Grade III } & \\
\hline & & Count & $\%$ & Count & $\%$ & \\
\hline \multirow[t]{3}{*}{ Mass shape } & Oval/round & 5 & 10.4 & 0 & 0.0 & 1.0 \\
\hline & Irregular & 43 & 98.6 & 4 & 100.0 & \\
\hline & Total & 48 & 100.0 & 4 & 100.0 & \\
\hline \multirow[t]{2}{*}{ Mass margin } & Non-circumscribed & 48 & 100 & 4 & 100.0 & - \\
\hline & Total & 48 & 100.0 & 4 & 100.0 & \\
\hline \multirow[t]{3}{*}{ Mass orientation } & Parallel & 8 & 16.7 & 1 & 25.0 & 0.544 \\
\hline & Not parallel & 40 & 83.3 & 3 & 75.0 & \\
\hline & Total & 48 & 100.0 & 4 & 100.0 & \\
\hline \multirow[t]{3}{*}{ Mass posterior features } & No/enhancement & 19 & 39.6 & 1 & 25.0 & 1.0 \\
\hline & Shadowing/combined & 29 & 60.4 & 3 & 75.0 & \\
\hline & Total & 48 & 100.0 & 4 & 100.0 & \\
\hline \multirow[t]{3}{*}{ Mass echopattern } & Hypoechoic & 42 & 87.5 & 4 & 100.0 & 1.0 \\
\hline & Heterogenous & 6 & 12.5 & 0 & 0.0 & \\
\hline & Total & 48 & 100.0 & 4 & 100.0 & \\
\hline
\end{tabular}

Table 4 Association between status of estrogen receptors and ultrasound findings of breast cancers

\begin{tabular}{|c|c|c|c|c|c|}
\hline & & & \multicolumn{2}{|c|}{ Estrogen receptor } & \multirow{2}{*}{$\begin{array}{l}p \\
\text { value }\end{array}$} \\
\hline & & & Positive & Negative & \\
\hline \multirow[t]{4}{*}{ Shape } & Oval/round & Count & 6 & 4 & 0.036 \\
\hline & & $\%$ within & $12.0 \%$ & $44.4 \%$ & \\
\hline & Irregular & Count & 44 & 5 & \\
\hline & & $\%$ within & $88.0 \%$ & $55.6 \%$ & \\
\hline \multirow[t]{4}{*}{ Margin } & Circumscribed & Count & 3 & 1 & 0.494 \\
\hline & & $\%$ within & $6.0 \%$ & $11.1 \%$ & \\
\hline & Non-circumscribed & Count & 47 & 8 & \\
\hline & & $\%$ within & $94.0 \%$ & $88.9 \%$ & \\
\hline \multirow[t]{4}{*}{ Orientation } & Parallel & Count & 9 & 2 & 0.670 \\
\hline & & $\%$ within & $18.0 \%$ & $22.2 \%$ & \\
\hline & Not parallel & Count & 41 & 7 & \\
\hline & & $\%$ within & $82.0 \%$ & $77.8 \%$ & \\
\hline \multirow[t]{4}{*}{ Posterior features } & No/enhancement & Count & 20 & 4 & 1.000 \\
\hline & & $\%$ within & $40.0 \%$ & $44.4 \%$ & \\
\hline & Shadowing/ combined & Count & 30 & 5 & \\
\hline & & $\%$ within & $60.0 \%$ & $55.6 \%$ & \\
\hline \multirow[t]{4}{*}{ Echopattern } & Hypoechoic & Count & 46 & 7 & 0.224 \\
\hline & & $\%$ within & $92.0 \%$ & $77.8 \%$ & \\
\hline & Heterogenous & Count & 4 & 2 & \\
\hline & & $\%$ within & $8.0 \%$ & $22.2 \%$ & \\
\hline
\end{tabular}


Table 5 Association between status of progesterone receptors and ultrasound findings of breast cancer

\begin{tabular}{|c|c|c|c|c|c|}
\hline & & & \multicolumn{2}{|c|}{ Progesterone receptor } & \multirow{2}{*}{$\begin{array}{l}p \\
\text { value }\end{array}$} \\
\hline & & & Positive & Negative & \\
\hline \multirow[t]{4}{*}{ Shape } & Oval/round & Count & 4 & 6 & 0.026 \\
\hline & & $\%$ within PR & $9.5 \%$ & $35.3 \%$ & \\
\hline & Irregular & Count & 38 & 11 & \\
\hline & & $\%$ within PR & $90.5 \%$ & $64.7 \%$ & \\
\hline \multirow[t]{4}{*}{ Margin } & Circumscribed & Count & 1 & 3 & 0.068 \\
\hline & & $\%$ within PR & $2.4 \%$ & $17.6 \%$ & \\
\hline & Non-circumscribed & Count & 41 & 14 & \\
\hline & & $\%$ within PR & $97.6 \%$ & $82.4 \%$ & \\
\hline \multirow[t]{4}{*}{ Orientation } & Parallel & Count & 7 & 4 & 0.713 \\
\hline & & $\%$ within PR & $16.7 \%$ & $23.5 \%$ & \\
\hline & Not parallel & Count & 35 & 13 & \\
\hline & & $\%$ within PR & $83.3 \%$ & $76.5 \%$ & \\
\hline \multirow[t]{4}{*}{ Posterior features } & No/enhancement & Count & 16 & 8 & 0.526 \\
\hline & & $\%$ within PR & $38.1 \%$ & $47.1 \%$ & \\
\hline & Shadowing/ combined & Count & 26 & 9 & \\
\hline & & $\%$ within PR & $61.9 \%$ & $52.9 \%$ & \\
\hline \multirow[t]{4}{*}{ Echopattern } & Hypoechoic & Count & 38 & 15 & 1.000 \\
\hline & & $\%$ within PR & $90.5 \%$ & $88.2 \%$ & \\
\hline & Heterogeneous & Count & 4 & 2 & \\
\hline & & $\%$ within PR2 & $9.5 \%$ & $11.8 \%$ & \\
\hline
\end{tabular}

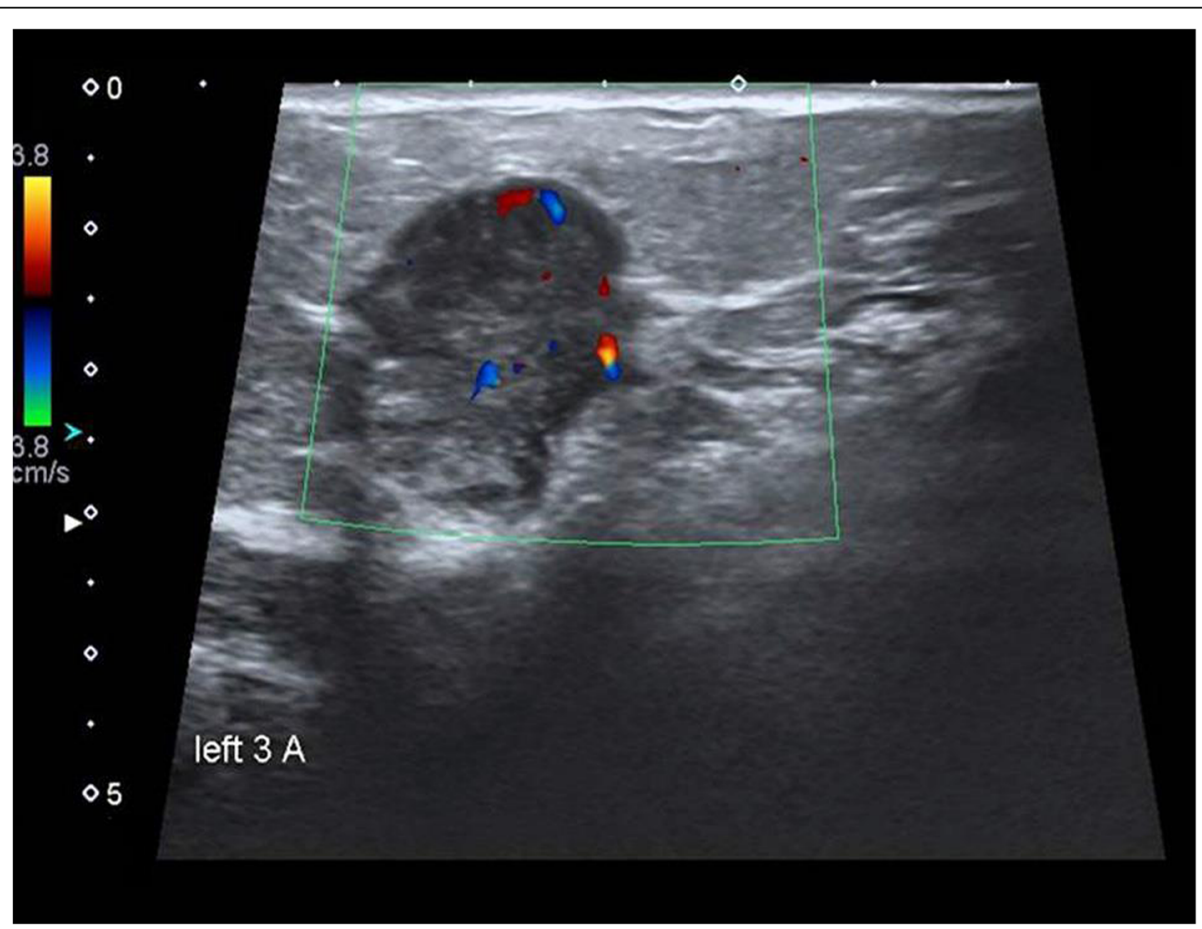

Fig. 4 B mode ultrasound revealed hypoechoic irregular shaped mass with speculated margin, antiparallel orientation, and no posterior features. On CCDI, it shows internal vascularity, assessed as BIRADS 5. Pathology: invasive ductal carcinoma (grade I). Biological markers: ER positive, PR positive, HER/neu-2 negative, and Ki67 negative 
Table 6 Association between status of Her-2/neu and ultrasound findings of breast cancer

\begin{tabular}{|c|c|c|c|c|c|}
\hline & & & Her-2/ne & & $p$ \\
\hline & & & Positive & Negative & value \\
\hline Shape & Oval/round & Count & 5 & 5 & 0.510 \\
\hline & & $\%$ within & $14.3 \%$ & $20.8 \%$ & \\
\hline & Irregular & Count & 30 & 19 & \\
\hline & & $\%$ within & $85.7 \%$ & $79.2 \%$ & \\
\hline Margin & Circumscribed & Count & 3 & 1 & 0.639 \\
\hline & & $\%$ within & $8.6 \%$ & $4.2 \%$ & \\
\hline & Non-circumscribed & Count & 32 & 23 & \\
\hline & & $\%$ within & $91.4 \%$ & $95.8 \%$ & \\
\hline Orientation & Parallel & Count & 5 & 6 & 0.299 \\
\hline & & $\%$ within & $14.3 \%$ & $25.0 \%$ & \\
\hline & Not parallel & Count & 30 & 18 & \\
\hline & & $\%$ within & $85.7 \%$ & $75.0 \%$ & \\
\hline Posterior features & No/enhancement & Count & 14 & 10 & 0.898 \\
\hline & & $\%$ within & $40.0 \%$ & $41.7 \%$ & \\
\hline & Shadowing/ combined & Count & 21 & 14 & \\
\hline & & $\%$ within & $60.0 \%$ & $58.3 \%$ & \\
\hline Echopattern & Hypoechoic & Count & 31 & 22 & 1.000 \\
\hline & & $\%$ within & $88.6 \%$ & $91.7 \%$ & \\
\hline & Heterogenous & Count & 4 & 2 & \\
\hline & & $\%$ within & $11.4 \%$ & $8.3 \%$ & \\
\hline
\end{tabular}

Table 7 Association between status of Ki67 and ultrasound findings of breast cancer

\begin{tabular}{|c|c|c|c|c|c|}
\hline & & & \multicolumn{2}{|c|}{ K176 receptor } & \multirow{2}{*}{$\begin{array}{l}p \\
\text { value }\end{array}$} \\
\hline & & & Positive & Negative & \\
\hline \multirow[t]{4}{*}{ Shape } & Oval/round & Count & 5 & 5 & 0.050 \\
\hline & & $\%$ within & $11.4 \%$ & $33.3 \%$ & \\
\hline & Irregular & Count & 39 & 10 & \\
\hline & & $\%$ within & $88.6 \%$ & $66.7 \%$ & \\
\hline \multirow[t]{4}{*}{ Margin } & Circumscribed & Count & 1 & 3 & 0.047 \\
\hline & & $\%$ within & $2.3 \%$ & $20.0 \%$ & \\
\hline & Non-circumscribed & Count & 43 & 12 & \\
\hline & & $\%$ within & $97.7 \%$ & $80.0 \%$ & \\
\hline \multirow[t]{4}{*}{ Orientation } & Parallel & Count & 8 & 3 & 1.000 \\
\hline & & $\%$ within & $18.2 \%$ & $20.0 \%$ & \\
\hline & Not parallel & Count & 36 & 12 & \\
\hline & & $\%$ within & $81.8 \%$ & $80.0 \%$ & \\
\hline \multirow[t]{4}{*}{ Posterior features } & No/enhancement & Count & 16 & 8 & 0.248 \\
\hline & & $\%$ within & $36.4 \%$ & $53.3 \%$ & \\
\hline & Shadowing/ combined & Count & 28 & 7 & \\
\hline & & $\%$ within & $63.6 \%$ & $46.7 \%$ & \\
\hline \multirow[t]{4}{*}{ Echopattern } & Hypoechoic & Count & 39 & 14 & 1.000 \\
\hline & & $\%$ within & $88.6 \%$ & $93.3 \%$ & \\
\hline & Heterogenous & Count & 5 & 1 & \\
\hline & & $\%$ within & $11.4 \%$ & $6.7 \%$ & \\
\hline
\end{tabular}




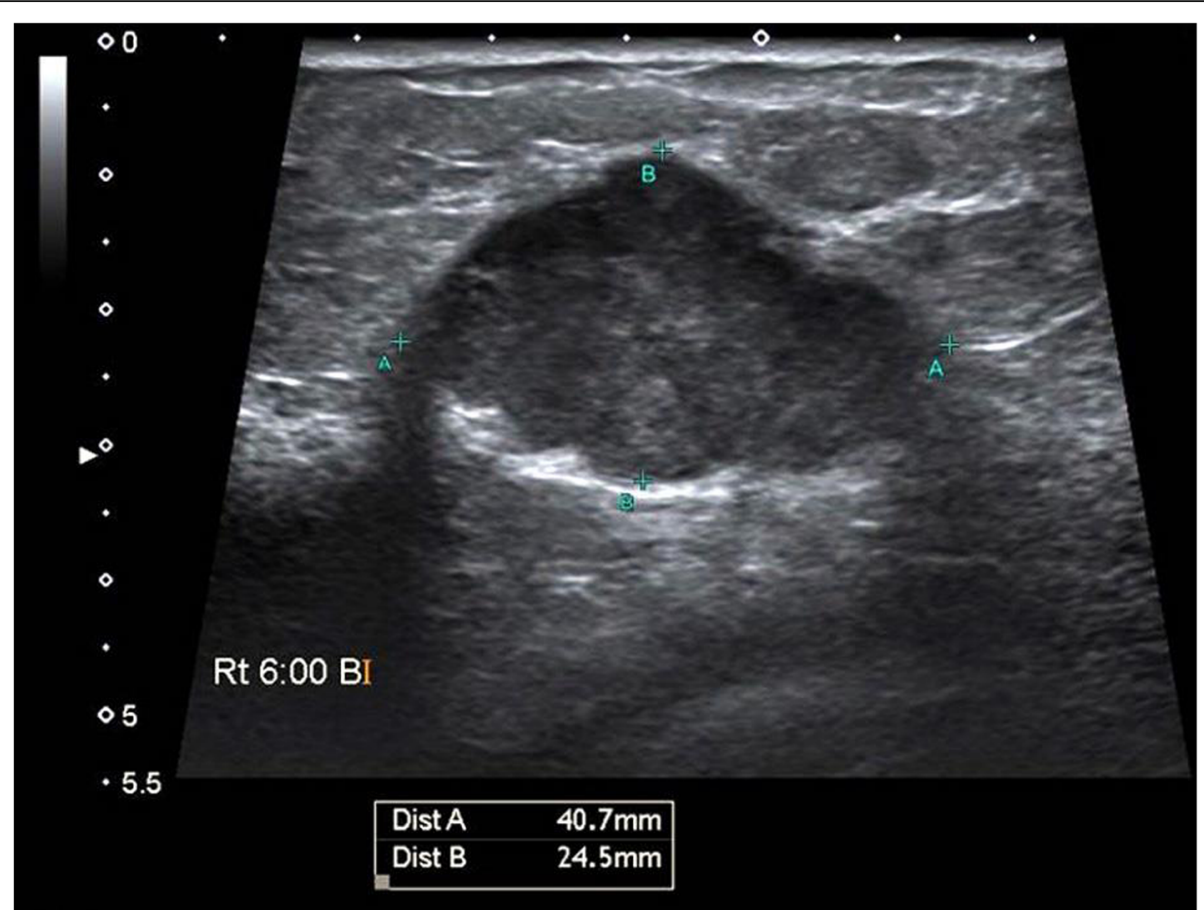

Fig. 5 B mode US shows oval-shaped hypoechoic solid mass with lobulated margin, parallel orientation, and posterior enhancement, and it measures about $40 \times 24 \mathrm{~mm}$ assessed as BIRADS 4b. Pathology: true cut biopsy revealed DCIS (grade 2). Biological markers: ER positive, PR positive, HER/neu-2 negative, and Ki67 negative

statistically significant difference in orientation and echopattern in differentiating between invasive cancer and DCIS ( $p$ value $=1.000$ and 0.543 , respectively). They reported that irregular shape, non-circumscribed margin, and no posterior features were the most important descriptors in differentiation between tumor types.

Out of the 13 cases of DCIS included in this study, 6 cases were non-mass forming malignancies (parenchymal distortion); in another way, all malignant cases assessed as NMLs were DCIS. Our results are comparable with the study done by Lee et al. [12]. They noted that NMLs were more frequently related with malignancies such as ductal carcinoma in situ (DCIS).

The association between tumor grade of invasive cancer and US findings in previous studies was varied. Watermann et al [13] reported that tumor grading did not significantly influence US descriptors characteristics; on the other hand, Lamb et al. [14] found that highgrade invasive cancer were more likely to demonstrate posterior acoustic enhancement and well-defined margins. Further studies $[10,15]$ observed that noncircumscribed margin and hypoechoic or heterogeneous echo patterns were more frequent in grade 3 than in grade 1 and 2 invasive cancers. In our study, we observed no statistical significant difference between low (Fig. 4)/medium (Fig. 1) and high-grade (Fig. 2) tumor type as regards the examined US descriptors (shape, margin, orientation, posterior feature, and echopattern) ( $p$ values $1.0,0,0.544,1.0$, and 1.0 , respectively). It is likely that the difference between all the previous studies including our results is reliant on the microstructure of the tumors, and this needs further studies.

In this study, we also correlated the US descriptors in breast cancer cases with the biological markers (estrogen, progesterone, HER-2/neu2, and KI 67). As regards the association between the US descriptors and the state of estrogen receptors, we found that irregular shape (88\%) was the most important descriptor in estrogenpositive breast cancers $(p$ value $=0.036)$. Our results reported that there were no statistically significant difference as regard mass margin ( $p$ value $=0.494)$. Our result are comparable with An et al. [9], who reported that irregular shape had a statistically significant difference $(p$ value $=0.005$ ) while there was no statistically significant difference as regards mass margin, posterior features, and echopattern in ER-positive cases ( $p$ value $0.83,1.00$, and 0.534 , respectively). Our results are in agreement with the study done by Costantini et al. [15], who reported that antiparallel orientation was more frequent in ER-positive breast cancers 41 (82.0\%) but with no statistically significant difference. Our results are in disagreement with the study done by Kim et al. [10], who reported that hypoechoic/complex echopattern, shadowing/combined posterior features, and anti-parallel 
orientation have statistically significant association in ER-positive cases ( $p$ value $0.0033,0.0566$, and 0.0190 , respectively).

As regards the association between the US descriptors with the state of progesterone receptors, we found that irregular shape and non-circumscribed margins were the most important descriptor in PR-positive breast cancers ( $p$ value $=0.026$ and 0.068 , respectively) respectively. This is in agreement with Moon et al. [21], who reported that irregular shape is frequently associated with progesterone receptor-positive cases ( $p$ value $=0.005)$ and Costantini et al. [15], who reported that non-circumscribed speculated margins are more frequently associated with progesterone positivity ( $p$ value $=0.009$ ). In our study, there were no statistically significant difference in other US descriptor (orientation, echopattern, and posterior features) when correlated with the state of progesterone receptors ( $p$ value $=0.713,0.526$, and 1.000 , respectively).

As regards the US correlation with the HER-2/neu oncogene expression, we found that there were no statistically significant difference between US descriptors (shape, margin, orientation, echopattern, and posterior features) and HER-2/neu state ( $p$ value $0.510,0.639$, $0.299,0.898$, and 1.000 , respectively). This is in agreement with Kim et al. [10], who reported that there were no statistically significant difference between us descriptors (shape, margin, orientation, echopattern, and posterior feature) and HER-2/neu state ( $p$ value $=0.2521$, $0.8243,0.5334,0.7620$, and 0.2242 , respectively). This also was in agreement with Cho et al. [16], who reported that there were no statistically significant difference as regards US descriptors (shape, margin, and orientation) and HER-2/neu state ( $p$ value $=0.173,0.99$, and 0.201 , respectively).

As regards the US correlation with the ki67-positive breast cancer cases, we found that irregular shape and non-circumscribed margin are more frequent with ki76positive cases with statistically significant difference ( $p$ value $=0.050$ and 0.047 , respectively). We concluded that there were no statistical significant association between ki76-positive breast cancers and US descriptors (echopattern and posterior feature) ( $p$ value $=1.000$ and 0.248 , respectively). Our results are comparable with Costantini et al. [15]. They concluded that echopattern and posterior features did not attain the level of statistical significance ( $p$ value 0.248 and 1.000 , respectively).

\section{Conclusion}

Finally, we concluded that irregularly shaped tumors with speculated margins were frequently seen in invasive duct carcinoma and also more frequently seen in ER-, PR-, and Ki67-positive cases. No relation between ultrasound descriptors and the tumor grade of invasive duct carcinoma. Also, there were no relation between ultrasound descriptors and the state of HER-2/neu. So, ultrasound may be helpful in prediction of tumor response to therapy and prediction of prognosis in cases of breast cancer.

\section{Abbreviations \\ ACR: American College of Radiology; BI-RADS: Breast imaging reporting and data system; DCIS: Duct carcinoma in situ; ER: Estrogen receptor; \\ HER: Human epithelial growth factor receptor; IQR: Interquartile range; PR: Progesterone receptor; SD: Standard deviation; SPSS: Statistical Package for Social Sciences; US: Ultrasound; WHO: World Health Organization}

\section{Acknowledgements}

Not applicable.

\section{Authors' contributions}

SE revised the collected data and the manuscript. DM performed US for all patients; found the correlation between the US findings and tumor type, grade, and state of biological markers; and wrote the manuscript. YA performed the statistical analysis. All authors read and approved the final manuscript.

\section{Funding}

No funding resources.

\section{Availability of data and materials}

The datasets used and/or analyzed during the current study are available from the corresponding author on reasonable request.

\section{Ethics approval and consent to participate}

The study was approved by our institution's ethics committee (Mansoura Faculty of Medicine Institutional Research Board) (ethics committee reference number is MS/17. 02. 25), and all patients gave their written informed consent before inclusion in the study.

\section{Consent for publication}

All patients included in this research gave written informed consent to publish the data contained within this study. If the patient was less than 16 years old, deceased, or unconscious when consent for publication was requested, written informed consent for the publication of this data was given by their parent or legal guardian.

\section{Competing interests}

The authors declare that they have no competing interests.

\section{Author details}

${ }^{1}$ Diagnostic Radiology and Medical Imaging, Ministry of Health, Cairo, Egypt. ${ }^{2}$ Diagnostic Radiology and Medical Imaging, Faculty of Medicine, Mansoura University, Mansoura, Egypt.

Received: 23 June 2019 Accepted: 16 September 2019

Published online: 21 November 2019

\section{References}

1. Buchberger W, Dekoekkoek-Doll P, Springer P, Obrist P, Dünser M (1999) Incidental findings on sonography of the breast: clinical significance and diagnostic workup. AJR. 173:921-927. https://doi.org/10.2214/ajr.173.4. 10511149

2. Gordon PB, Goldenberg SL (1995) Malignant breast masses detected only by ultrasound. Cancer. 76:626-630 PMID: 8625156

3. American College of Radiology (2013) Breast imaging reporting and data system (BI-RADS), 5th edn. American College of Radiology, Reston

4. Clark G (2000) Diseases of the breast, 2nd edn. Lippingcott Williams \& Wilkins, Philadelphia

5. Van Diest PJ, van der Wall E, Baak JP (2004) Prognostic value of proliferation in invasive breast cancer: a review. J Clin Pathol 57:675-681. https://doi.org/ 10.1136/jcp.2003.010777

6. Rosen PP (2001) Rosen's breast pathology 2nd edn. Lippingcott Williams \& Wilkins, Philadelphia 
7. Pegram MD, Konecny GE, O'Callaghan C, Beryt M, Pietras R, Slamon DJ (2004) Rational combinations of trastuzumab with chemotherapeutic drugs used in the treatment of breast cancer. J Natl Cancer Inst 96:739-749 https://doi.org/10.1093/inci/djh131

8. Marino MA, Riedl CC, Bernathova M, Bernhart C, Baltzer PAT, Helbich TH et al (2018) Imaging phenotypes in women at high risk for breast cancer on mammography, ultrasound, and magnetic resonance imaging using the fifth edition of the breast imaging reporting and data system. Eur J Radiol 106:150-159 https://doi.org/10.1016/j.ejrad.2018.07.026

9. An YY (2015) Breast cancer in very young women (<30 years): correlation of imaging features with clinicopathological features and immunohistochemical subtypes. Eur J Radiol 84:1894-1902

10. Kim SH, Seo BK, Lee J, Kim SJ, Cho KR, Lee KY et al (2008) Correlation of ultrasound findings with histology, tumor grade, and biological markers in breast cancer. Acta Oncol 47:1531-1538. https://doi.org/10.1080/ 02841860801971413

11. Scoggins ME, Fox PS, Kuerer HM, Rauch GM, Benveniste AP, Park YM et al (2015) Correlation between sonographic findings and clinicopathologic and biologic features of pure ductal carcinoma in situ in 691 patients. Am J Roentgenol 204:878-888. https://doi.org/10.2214/AJR.13.12221

12. Lee J, Lee JH, Baik S, Cho E, Kim DW, Kwon HJ et al (2016) Non-mass lesions on screening breast ultrasound. Med uUltrasonography 18:446-451. https:// doi.org/10.11152/mu-871

13. Watermann DO, Tempfer CB, Hefler LA, Parat C, Stickeler E (2005) Ultrasound criteria for ductal invasive breast cancer are modified by age, tumor size, and axillary lymph node status. Breast Cancer Res Treat 89:127

14. Lamb PM, Perry NM, Vinnicombe SJ, WELLS CA (2000) Correlation between ultrasound characteristics, mammographic findings and histological grade in patients with invasive ductal carcinoma of the breast. Clin Radiol 55:4044. https://doi.org/10.1053/crad.1999.0333

15. Costantini M, Belli P, Bufi E, Asunis AM, Ferra E, Bitti GT (2016) Association between sonographic appearances of breast cancers and their histopathologic features and biomarkers. J Clin Ultrasound 44:26-33 https:// doi.org/10.1002/jcu.22312

16. Cho N (2016) Molecular subtypes and imaging phenotypes of breast cancer Ultrasonography 35:281. https://doi.org/10.14366/usg.16030

17. Torre LA, Bray F, Siegel RL, Ferlay J, Lortet-Tieulent J, Jemal A (2015) Global cancer statistics, 2012. CA Cancer J Clin 65:87-108. https://doi.org/10.3322/ caac. 21262

18. Azim HA, Ibrahim AS (2014) Breast cancer in Egypt, China and Chinese: statistics and beyond. J Thorac Dis 6:864-866. https://doi.org/10.3978/j.issn. 2072-1439.2014.06.38

19. Wu LZ, Han RQ, Zhou JY, Yang J, Dong MH, Qian Y et al (2014) Incidence and mortality of female breast cancer in Jiangsu, China. Asian Pac J Cancer Prev 15:2727-2732. https://doi.org/10.7314/apjcp.2014.15.6.2727

20. Euhus D, Di Carlo PA, Khouri NF (2015) Breast cancer screening. Surg Clin 95:991-1011. https://doi.org/10.1016/j.suc.2015.05.008

21. Moon HJ, Kim EK, Kim MJ, Yoon JH, Park VY (2019) Comparison of clinical and pathologic characteristics of ductal carcinoma in situ detected on mammography versus ultrasound only in asymptomatic patients. Ultrasound Med Biol 45:68-77. https://doi.org/10.1016/j.ultrasmedbio.2018. 09.003

\section{Publisher's Note}

Springer Nature remains neutral with regard to jurisdictional claims in published maps and institutional affiliations.

\section{Submit your manuscript to a SpringerOpen ${ }^{\circ}$ journal and benefit from:}

- Convenient online submission

- Rigorous peer review

- Open access: articles freely available online

- High visibility within the field

- Retaining the copyright to your article

Submit your next manuscript at $\boldsymbol{\nabla}$ springeropen.com 